\title{
DIE PHASENGLIEDERUNG DER EISRANDLAGEN DES WÜRMEISZEITLICHEN REUSSGLETSCHERS IM ZENTRALEN SCHWEIZERISCHEN MITTELLAND
}

\author{
- Hans Annaheim, Alfrfo Bögli und Samuel Moser
}

Durch das weite, vom mächtigen Pfeiler des Rigi zweigeteilte Alpentor zwischen Pilatuskette und Roßberg traten die beiden Arme des würmeiszeitlichen Reußgletschers, an der linken Flanke verstärkt durch den Brünigarm des Aaregletschers, auf das Alpenvorland hinaus. Nördlich des Rigi-Nunataks vereinigten sich die beiden Eisströme, deren Oberfläche hier in ca. $1100 \mathrm{~m}$ Höhe lag, zu einem breiten Vorlandgletscher. Dieser überflutete die wenig hohe Wasserscheide zwischen Emmenberg und Lindenberg und drang über sie hinweg und durch die geräumige Weitung des obern Freiamtes in jenen zentralen Abschnitt des Molasselandes ein, der durch die sechs gleichlaufenden Talfurchen charakterisiert wird, welche, der allgemeinen Abdachung des Mittellandes folgend, zur Jurafußniederung hinziehen. Zunächst noch in nur durch den breiten Rücken des Lindenberges aufgespaltener breiter Front vorrückend, gliederte sich die Eismasse mit zunehmender Ausdünnung schließlich in sechs wohl individualisierte Zungen auf, ganz im Gegensatz zu den breiten Eisfächern des Rhonegletschers im westlichen und des Rheingletschers im östlichen Mittelland. Entsprechend der allmählichen Erniedrigung der Wasserscheidenregion vom Emmenberg (W) in östlicher Richtung bis zur tiefsten Stelle, wo das Reußtal aus der durch das Streichen der subalpinen Molasse vorgezeichneten Subsequenzzone in die Abdachungsrichtung nordwärts einbiegt, drangen die Eiszungen desto weiter nordwärts vor, je weiter östlich sie lagen. Vermochte der Rottalarm nur $21 \mathrm{~km}$ über die Emme-Reuß-Linie nordwärts vorzustoßen, so erreichten die lange Seetalzunge und die am Ende zweigeteilte, mächtige, das Bünz- und Reußtal durchströmende Eismasse fast den Jurafuß; lediglich die schwache, durch die hohe Molasseschwelle von Hildisrieden gehemmte Zunge des Winentales blieb zwischen dem Seetalarm und dem nordwärts in drei Lappen diffluierenden Suhrentalast weiter zurück (s. Fig. 1, Tab. 2).

F. J. KAUFMANN hat als erster auf den grundlegenden morphologischen Gegensatz zwischen extra- und intramoränen Gebieten des zentralen Mittellandes aufmerksam gemacht. Mit der Morphologie der in so auffallender Weise durch den würmeiszeitlichen Gletscher geprägten, an Seiten- und Endmoränenwällen, Drumlinformen, Schotterbildungen und Hinterfüllungen reichen intramoränen Landschaft haben sich dann - um nur die größeren Arbeiten zu nennen insbesondere F. MÜhlbERG, dann O. FREY und in neuerer Zeit H. JäCKLI, J. KopP und S. Moser befaßt. Dank der engen Nachbarschaft der einzelnen Eiszungen und ihrer Zugehörigkeit zum gleichen Stammgletscher wurden die großen Zusammenhänge der bedeutenden Moränenzüge, deren Aufteilung in verschiedene Eisrandlagen und ihre Parallelisierung im Reußgletschergebiet bald erkannt, sodaß fußend auf den Forschungen von MühlberG, schon BRÜCKNER (Penck und Brückner, 1909, Bd. 2, p. 496 ff.) und HeIm (1919, Bd. 1, p. 258 f., Taf. XI, XIa) davon relativ einläßliche zusammenfassende Darstellungen zu geben vermochten.

Die genannten Forscher nahmen an, daß der Ablauf der Würmvereisung durch einen kontinuierlichen Vorstoß bis zu den äußersten Jungmoränen und einen darauffolgenden Rückzug mit eingeschalteten Haltephasen gekennzeichnet sei. Schon der ausgezeichnete Beobachter F. MÜHLBERG stellte jedoch - wohl als erster - einen auffallenden Formunterschied zwischen den Endmoränen der mittleren der drei wohl ausgebildeten Eisrandlagen gegenüber der äußersten und der rückwärtigen Phase fest: «Mehrere Kilometer weiter zurück liegen (Triengen im Surtal, Nordende des Hallwilersees im Seetal) flache breite Moränenwälle, die so verwischt aussehen, als ob sie aus früheren normalen Wällen durch darüber vordringende Gletscher umgestaltet worden wären». Die beiden Wälle bei Hitzkirch bezeichnet er dagegen ausdrücklich als «wohl markiert» (1910, p. 38, ähnlich auch 1911, p. 166). Leider hat er diese grundsätzlich so bedeutsamen Feststellungen nicht weiter verfolgt. Später hat dann J. KNAUER seine einer überfahrenen Endmoränenphase geltenden Untersuchungen aus dem Ostalpenvorland auch auf die 


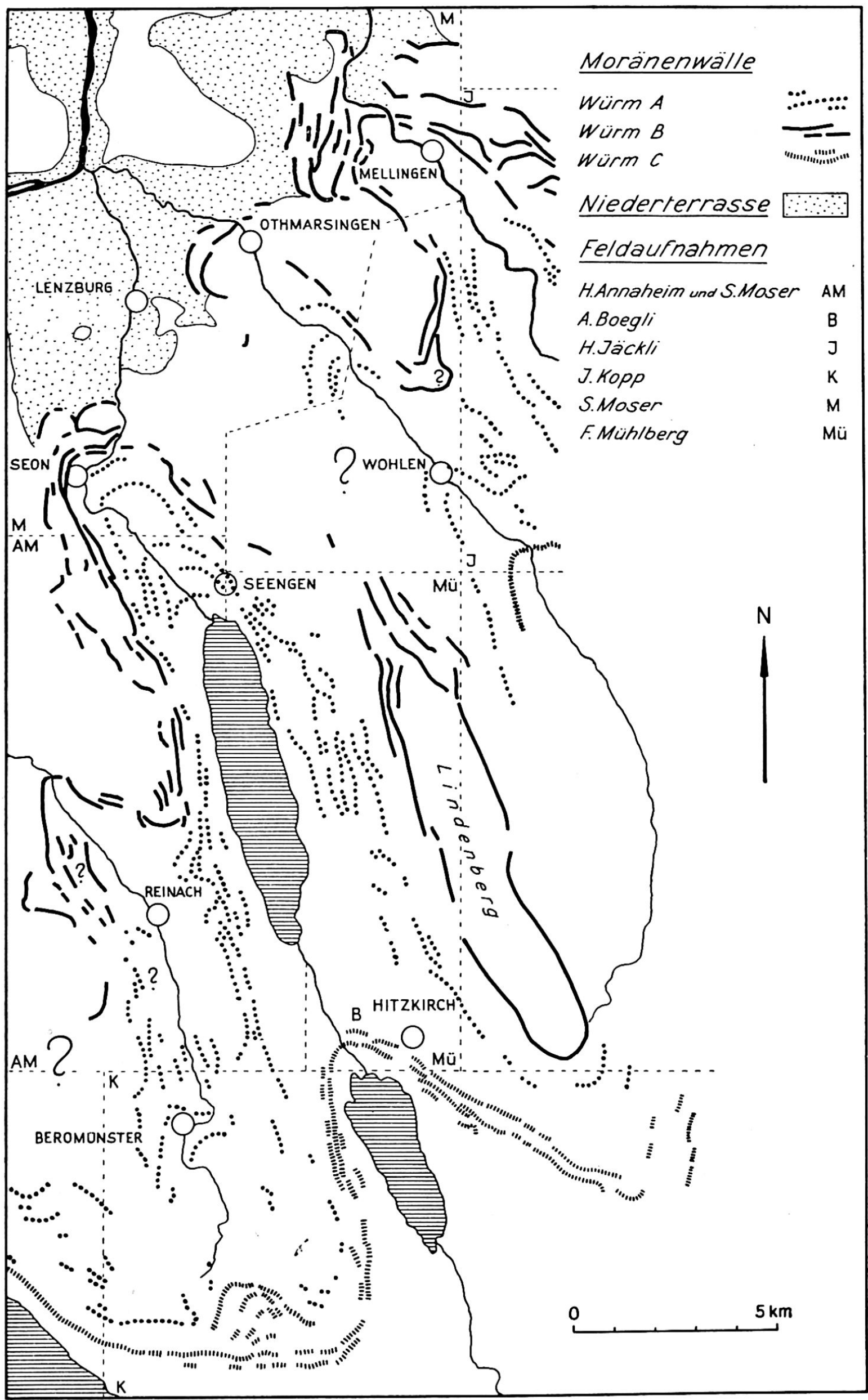

Fig. 1 Karte der würmzeitlichen End- und Seitenmoränen des Winen-, See- und Bünztales und der Gegend von Mellingen (Entwurf H. Annaheim und S. Moser, Zeichnung B. Baur). 
Schweiz ausgedehnt und zunächst im Linthgletschergebiet (1938), sodann im Reußgletschergebiet (1954) die Zürichphase als später überfahrenen ersten würmzeitlichen Gletscherstand bezeichnet. Die schon seit 20.Jahren von H. AxNAHEIM im zentralen Mittelland durchgeführten Studien ergaben jedoch eine Bestätigung der Beobachtungen MüHLBERGs, und inzwischen mit A. BöGI.I und S. MOSER unternommene Begehungen führten zu den nämlichen Ergebnissen. Jüngst hat JäcKLI die Phasen des Reußtals untersucht und für die Moränen von Bremgarten die Auffassung KNAUERS ebenfalls abgelehnt. Es mag daher erwünscht sein, wenn die Verfasser ihre Befunde ebenfalls darlegen; sie stützen sich im besondern auf die im folgenden von Moser konzipierten Beobachtungen im untern Seetal und jene von BöGLI über die Endmoränen von Ermensee-Hitzkirch. Von einer weiter ausholenden Diskussion des mit diesen Erscheinungen zusammenhängenden Problemkomplexes sei abgesehen, da dazu die Beobachtungsgrundlagen noch nicht genügen.

Ihrer genetischen Auffassung entsprechend bezeichnen die Verfasser im folgenden die drei Haupteisrandlagen von außen nach innen als Phase B (äußere Jungmoränen, Maximalstand), Phase A und Phase C (innere Jungmoränen, «Zürichstadium»).

\section{Die Phase Würm B (Seon) im Seetal (Fig. 1-4)}

Die Seoner Phase umfaßt vier Moränenwälle. Der äußerste Wall ist relativ weit (über $500 \mathrm{~m}$ ) von den innern entfernt; er verläuft nördlich «Emmet» und «Biren» in zwei Halbkreisen quer über den Talboden. Er erhebt sich bis zu $11 \mathrm{~m}$ über seine Umgebung. Die Nordseite des Walles ist steiler als die südliche Innenseite, weil hier seinem Fuß eine mächtige Moränendecke aufliegt. In den Molassehügeln östlich des Aabaches fehlt eine Fortsetzung des Walles; am westlichen Talhang erkennt man ihn auf kurze Strecken südwestlich Seon, wo er zur Bildung der Hinterfüllungen des «Schliertels» und des «Fröschenmooses» Anlaß gegeben hat.

Zwischen Wall 1 und Wall 2 konnte anhand von drei Schotteraufschlüssen in Kiesgruben gezeigt werden, daß die Seoner Moränen auf den Niederterrassenschottern aufliegen; diese sind also akkumuliert worden, bevor der maximale Gletscherstand erreicht war (vgl. MOSER).

Der zweite Wall ist höher als der erste und weist kleinere Unterbrüche auf; er ist besonders auf der westlichen Talseite auf lange Strecken hin in kurze Rücken aufgelöst. Er überquert den Aabach bei der «Sigismüli» und erscheint auf dem nach NW vorspringenden Sporn des Chrüzbigers nur als Streu von Erratikern.

Der dritte Bogen ist der mächtigste; er erhebt sich bis zu $25 \mathrm{~m}$ über die Umgebung. Er wird nur von engen Schmelzwasserausläufen durchbrochen. Der Wall ist überall zweiseitig geböscht, außer bei Retterswil. Ein markantes Tälchen trennt auf der Nordwestseite des Seoner Moränenkranzes den dritten Wall (Hügel des «Fornholzes») vom vierten. Es durchbricht dann als typisches Trompetentälchen die äußeren Wallbögen und läuft auf die Niederterrassen-Akkumulationsfläche aus. Im übrigen ist der vierte Wall aber immer dem dritten angelagert; er besitzt keine äußere, jedoch eine sehr steile innere Böschung. Auf der Westseite des Tales kann man ihn ununterbrochen verfolgen; östlich des Aabaches tritt er zuerst nur als kleiner Rest («Bäpperch») auf, dann als Moränenschleier und Erratikerstreu an der Flanke des Hätni. In Egliswil wird er durch eine mächtige Hinterfüllung abgelöst.

\section{Die Phase Würm A (Hallwil-Seengen)}

Die Phase von Hallwil-Seengen besitzt eine viel größere horizontale Ausdehnung als diejenige von Seon, ist doch der nördlichste $W$ all über $3 \mathrm{~km}$ vom südlichsten entfernt. Ein Rest des ersten Walles ist bei Seon südlich des W-E-gerichteten Laufabschnittes des Aabaches erhalten geblieben. Während er beinahe gesucht werden muß, präsentiert sich der zweite Wall als zusammenhängender sanfter Hügel von der Mühle südlich Seon über «Allmend» und «Betten» bis zur Burschmatt südlich Egliswil. Die zu diesen zwei Wällen gehörenden Seitenmoränen sind auf der westlichen Talseite westlich Hallwil zu finden; im E verschwinden sie an den Molassehängen. 
Die nächsten Wälle sind weiter zurückgestaffelt. In der Talmitte sind sie schlecht erkennbar; nur im Übergang zu den Seitenmoränen nehmen sie die Gestalt wohlgeformter, allerdings sanft geböschter Wälle an. Der dritte Wall verläuft über Hallwil, Spißmatt, Schlatt, Steinis, östlich Seengen. Der vierte Wall zieht sich über Boniswil, Ried, Oberschlatt, Kirche Seengen. Der fünfte Wall ist nur schwach angedeutet beim Schloß Hallwil.

\section{Die Formunterschiede zwischen den Wällen verschiedener Phasen}

Schon diese knappe Beschreibung der Seoner und Seengener Endmoränen hat gezeigt, daß die Wälle der zwei Phasen wesentliche Formunterschiede aufweisen. Vergleichen wir die Verhältnisse im Seetal mit denjenigen der benachbarten Täler, so läßt sich jedesmal erkennen, daß die Wälle der nördlichsten Phase (Maximalphase, Würm B) einen andern Formstil besitzen als diejenigen der im $S$ folgenden Phase Würm $A$. Kurz zusammengefaßt ergeben sich folgende Charakteristiken:

Würm B (z.B.Seon): Die Kammlinie der Wälle steigt auf und ab; streckenweise ist sie eine wirkliche Linie, streckenweise krönt aber ein breiter Rücken den Wall. Buckel scheinen dem Wall angesetzt, während, besonders auf der Innenseite, Steilböschungen $\mathrm{zu}$ finden sind, die von ganz verschiedener Größe sein können. Der Innenhang ist steiler als der Außenhang, sofern dieser nicht durch Schmelzwasser unterschnitten ist. Das Auf und Ab der Endmoränen setzt sich in die Seitenmoränen fort. Oft liegen auch Blöcke auf der Oberfläche.

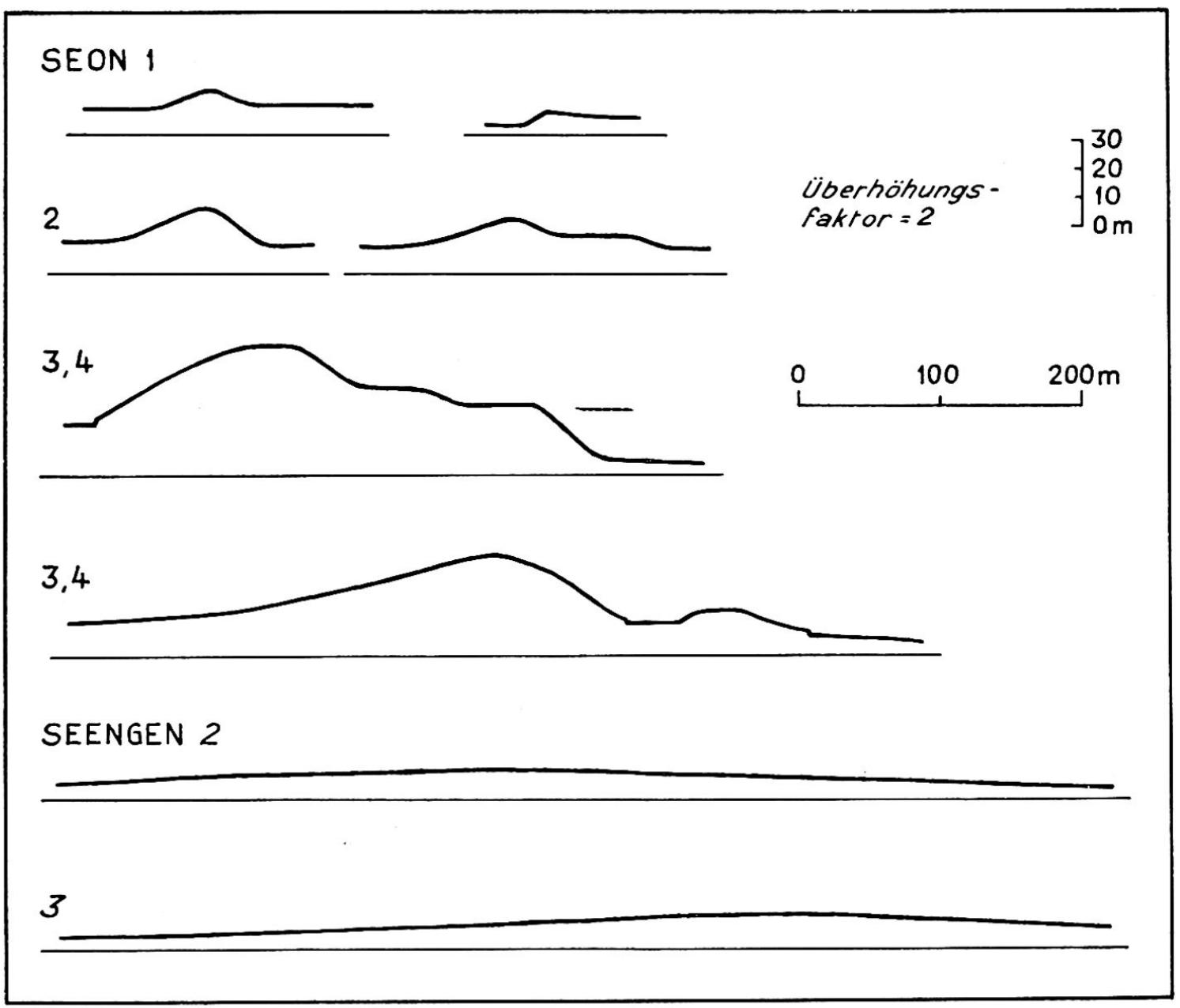

Fig. 2 Querprofile durch die Endmoränenwälle der Stadien Würm B (Seon) und Würm A (Seengen) (S. Moser). 


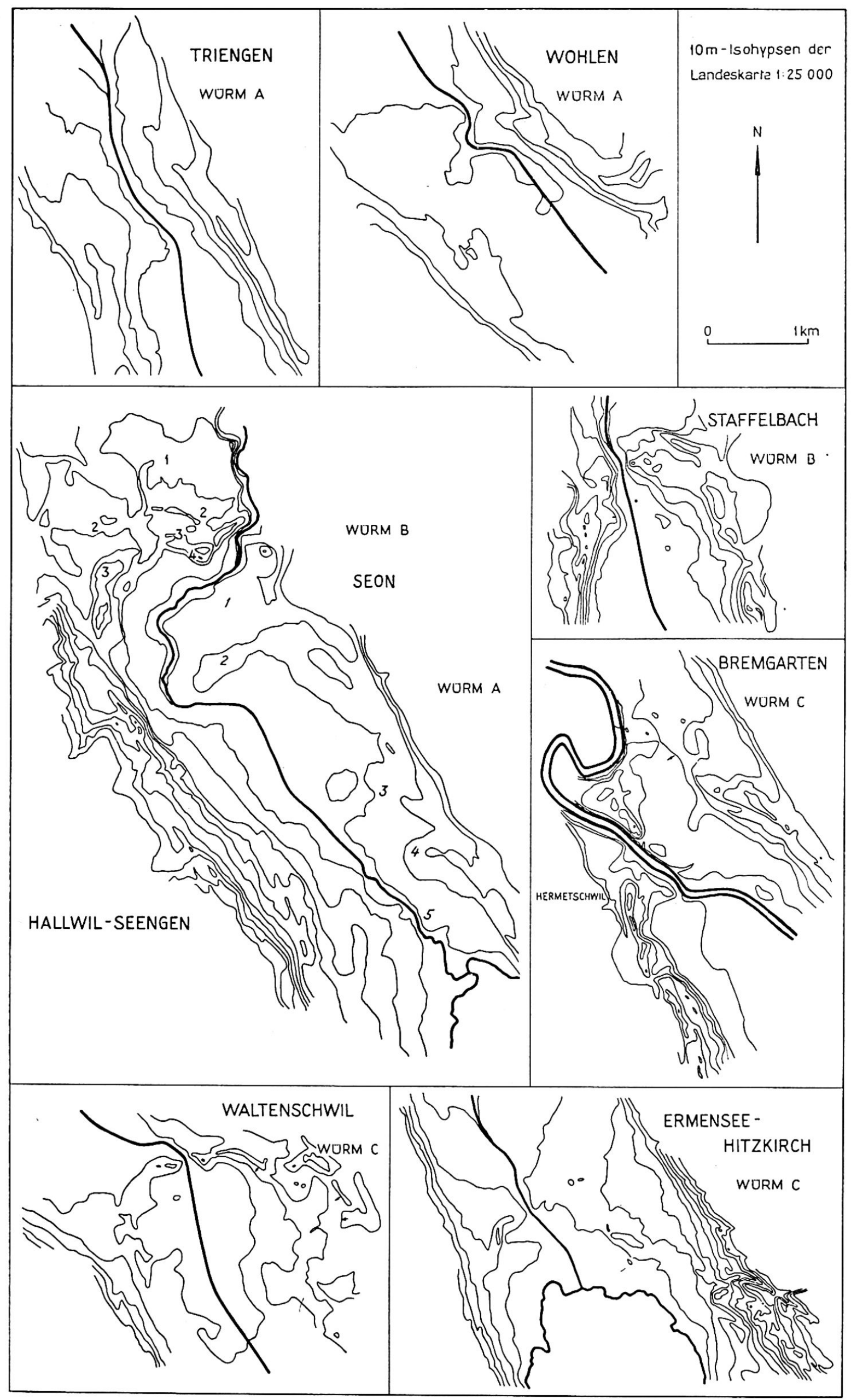

Fig. 3 Isohypsenbilder von Endmoränenphasen der Stadien Würm A, B und C im Suhren-, See-, Bünz- und Reußtal, nach der L. K. 1:25000 (Entwurf S. Moser, Zeichnung B. Baur). 
Würm A (z.B. Seengen): Die Endmoränen sind in der Talmitte nicht oder nur äußerst schwach angedeutet. Nur die seitlichen Teile der Stirnmoränen und die anschließenden Seitenmoränen erscheinen als Wälle. Diese sind wunderbar gleichmäßig im Anstieg nach hinten und in ihrer Form. Kuppen fehlen ihnen, ebenso Verbreiterungen oder kantenförmige Strecken in ihrer Kammlinie. Angesetzte Buckel sind unauffällig. Nicht in die Gesamtform passende Steilböschungen und oberflächliche Blöcke fehlen.

Da solche Beschreibungen, auch wenn sie auf detaillierter Feldaufnahme beruhen, subjektiven Einflüssen unterworfen sind, sollten objektive Methoden zur Differenzierung der zwei angedeuteten Formstile herangezogen werden. Die erste der hiernach beschriebenen Methoden ist nicht neu: Man zeichnet Querprofile durch die Endmoränenwälle. Das Resultat ist in Figur 2 zusammengestellt. Es zeigt sich eindeutig, daß die Wälle von Würm A (Seengen) viel breiter, flacher, niedrig und ausgeglichener sind als diejenigen der Phase $\mathrm{B}$ (Seon).

Die zweite Methode wurde schon von Troll (1936) und Knauer (1937) herangezogen, jedoch nicht konsequent ausgewertet. Sie besteht darin, daß man die Isohypsen - in unserem Falle der Landeskarte 1:25000 - herauszeichnet und ihren Verlauf in ganzen Gebiet eines Moränenbogens, aber auch auf dem Wall selber untersucht. Anhand von Fig. 3 lassen sich deutlich die Isohypsenbilder der Würm B - von denjenigen der Würm A-Phasen unterscheiden :

Würm B (Seon, Staffelbach): Die Kurven liegen nahe beieinander, besonders auf der Innenseite der Wälle. Sie treten bis auf ganz kurze Distanz an den Fluß oder an ein Schmelzwassertal heran. Den Wällen aufgesetzt erscheinen kleine geschlossene Kurven von unregelmäßiger Form und Größe. Auch die anschließenden Seitenmoränen sind so gestaltet.

Würm A (Seengen, Triengen, Wohlen) : Die Kurven liegen weit auseinander. In der Nähe der Talmitte laufen sie in großem Abstand auf weite Strecke dem Fluß nach. Beim Übergang in die Seitenmoränen richten sie sich zu parallelen Linien aus, die ohne Störungen weiterziehen. Geschlossene Kurven sind äußerst selten.

Die Anwendung der oben beschriebenen morphologischen Methoden auf die Moränenwälle der Phase Würm C läßt erkennen, daß ihre Formen mit denjenigen der Phase $B$, nicht aber mit denen von Würm $A$ verwandt sind (Fig. 3: Waltenschwil, Bremgarten und Hitzkirch). Demnach sind - wofür im folgenden noch mehr Beweise angeführt werden - diese Moränenwälle nicht überschliffen worden.

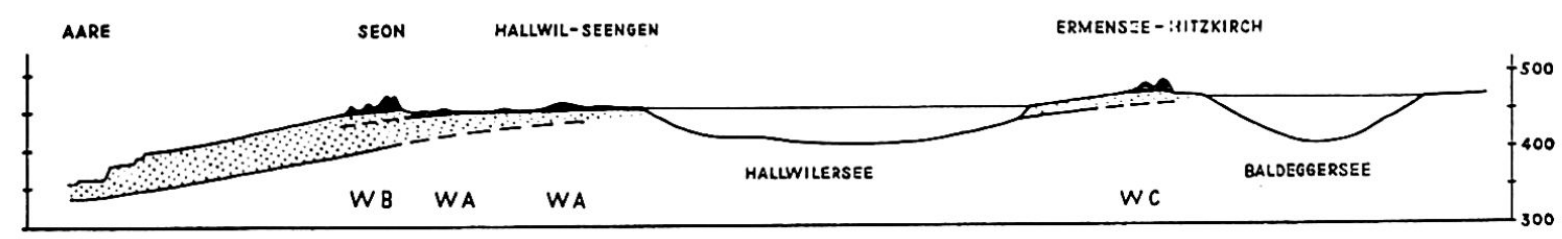

Fig. 4 Die Folge der Würmphasen im Längsprofil des Seetals (punktiert: Vorstoß-Schotter, zwischen Hitzkirch und Hallwilersee * Rückzugsschotter») (S. MOSER)

\section{Die Phase Würm $C$ (Fig. 9)}

Die Rückzugsphase von Ermensee-Hitzkirch bildet die südlichste der drei Stirnmoränengruppen am Seetalerlappen des Reußgletschers (Fig. 3). Die Moräne ordnet sich in den Moränenzug ein, der von Sursee, wo er den Sempachersee abschließt, über Hildisrieden und Römerswil in das Seetal verläuft, den Baldeggersee umrundet und über Lieli und Beinwil b/Muri in den Raum von Bremgarten gelangt (Fig. 1). Die Seitenmoränen, die zum Seetal hinunterführen, sind doppelt, gelegentlich sogar drei- 


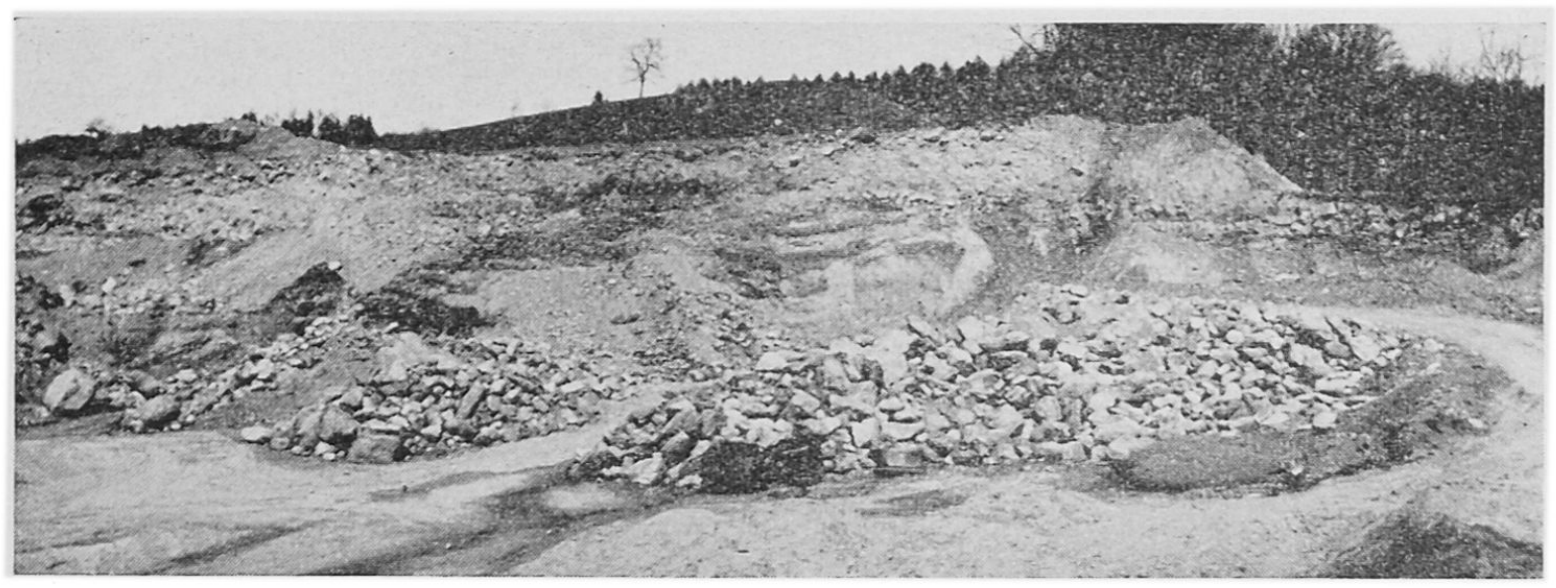

Fig. 5 Kiesgrube von Gelfingen: Über. Moräne ist in der Bildmitte noch der Schotter der Hinterfüllung angeschnitten. Über die Moräne und den Schotter legt sich ein Blockstreifen, der seinerseits von teilweise grobblockiger Moräne bedeckt ist (Photo A. BöGLI).

fach. Die Stirnmoränen sind teilweise glazifluvial zerstört und in Einzelhügel aufgelöst worden, was das Erkennen der beiden Hauptmoränenkränze erschwert. Es lassen sich unter den Hügeln zwei morphologische Typen unterscheiden; der eine besteht aus flachen drumloiden, der andere aus jung aussehenden, wallartigen Formen; jene gehören zum äußern, diese zum innern Moränenkranz.

Der äußere Moränenwall setzt im W mit dem Erreichen des Talgrundes aus und findet erst in $1 \frac{1}{2} \mathrm{~km}$ Entfernung in einigen flachen Resten des Großhübels eine Fortsetzung. Eine Lücke von $1200 \mathrm{~m}$ trennt diese Hügel vom einsetzenden Wall südlich von Hitzkirch. Er ist an den Talhang geklebt. Eine ebene Hinterfüllung auf $500 \mathrm{~m}$ Höhe ist durch die Seitenflüsse, vielleicht auch durch Oberflächenwasser vom Gletscher her entstanden. Die Kiesgrube von Gelfingen, die durch die Moräne hindurchgreift

Fig. 6 Kiesgrube Gelfingen Anschnitt der Hinterfüllung mit Schottern (Mitte), überlagert von Blockstreifen und Moräne, unterlagert von einer weniger blockigen Moräne (Photo A. Bögli).

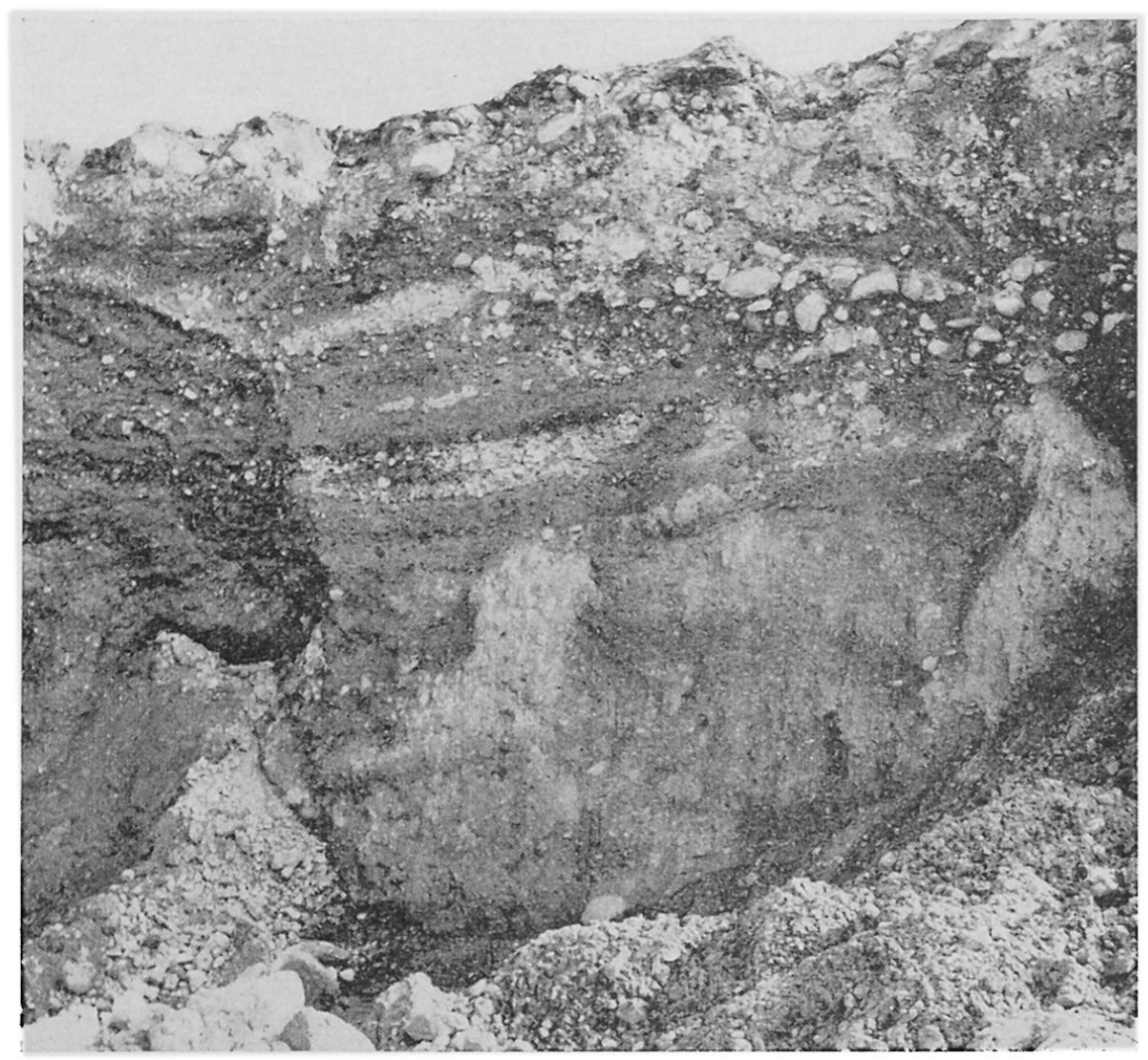




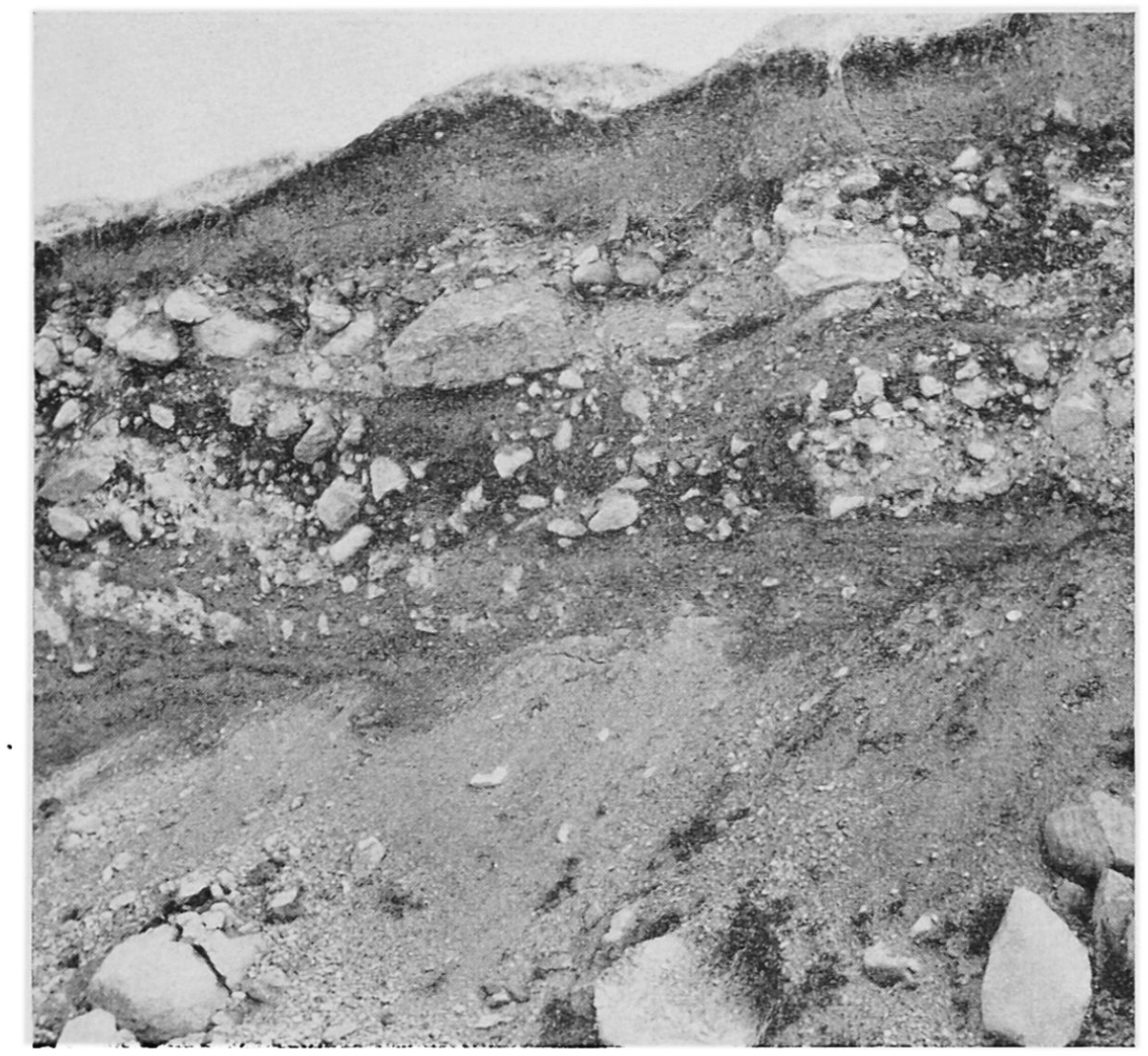

Fig. 7 Kiesgrube Gelfingen, Nordhälfte: Die grobblockige Obermoräne liegt unmittelbar auf derfeineren Untermoräne (Photo A. Bögli).

und die Hinterfüllung im östlichsten Teil noch eben berührt, gestattet, die Bildungsvorgänge bei der äußern Moräne zu erkennen (Fig. 5-7).

Im Hintergrund der Kiesgrube folgt über einer mächtigen Moränenlage gut geschichteter Schotter und zu oberst teilweise sehr grobblockige Moräne (Fig. 6). Im Nordteil fehlt der Schotter, da er ganz im Moränenwall liegt (Fig. 7). Das Profil zeigt, daß auf eine erste Moränenbildung entweder der Dünkelbach seine Schotter gegen den Gletscher zu vorschob, also schneller aufschotterte als die Moräne in die Höhe wuchs, oder daß er die Moräne erodierte. Die Berührungsfläche ist sehr unregelmäßig und durchaus diskordant. Die darüber liegenden grobblockigen Gletscherablagerungen, die nur wenig weit auf den Schotter übergreifen, verraten ein leichtes Anschwellen der Gletscherzunge, ohne daß deshalb gleich an einen neuen Vorstoß gedacht werden muß. Es handelt sich um Schwankungen kleinen Ausmaßes, wie sie zum Wesen jedes Gletschers gehören.

Hinter der Moräne flossen auf der Hinterfüllung Dünkel- und Schließbach gegen $\mathrm{N}$ und erodierten im Verein mit den Schmelzwassern den Moränenwall bei Hitzkirch so gründlich, daß eine große Lücke entstand. An Stelle des Walles trat eine entsprechende Fläche aus Schottern und verschwemmter Moräne. Es liegt eine ausgesprochene Übergangssituation vor, wo sich Schotter und Moräne innig verzahnen.

Nach Abschluß der ersten Phase zog sich der Gletscher geringfügig zurück. Es bestehen keine Beweise dafür, da $\beta$ es sich um mehr als eine jener kurzfristigen Schwankungen handelt, die für die Scharung von Moränenwällen von großer Bedeutung sind. Das Eis löste sich vom ersten Wall, um nach einiger Zeit wieder vorzustoßen, ohne das Ausmaß der ersten Phase zu erreichen. Daher liegt auf der Ostseite des Aabaches die innere Moräne gegen $300 \mathrm{~m}$ weiter im Innern des Zungenbeckens, während im W der Wall an den äußern angeschoben wurde.

Der innere Moränenwall ist am Erlosenhang gut entwickelt und findet in den Stirnmoränen im Herrenberg und Schützenhubel eine deutliche Fortsetzung. Dann 


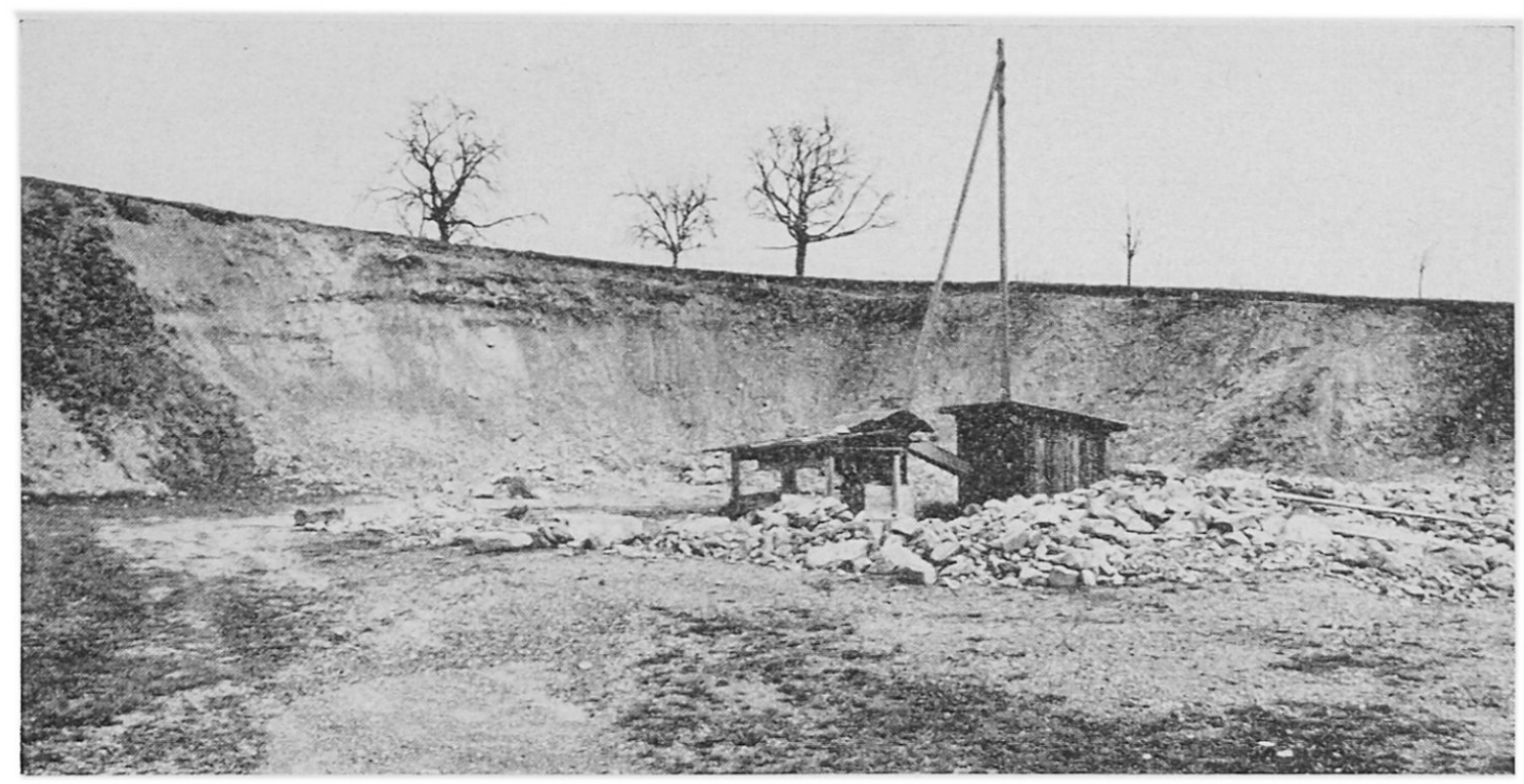

Fig. 8 Übersicht über die Herrenbergmoräne mit dem Vorstoßschotter, darüber abschließendem Blockstreifen und der Moräne des innern Moränengürtels (oben) (Photo A. BöGLI).

aber folgt eine beträchtliche Lücke bis zum östlichen Talhang, wo südlich des Dünkelbaches der Wall wieder sehr groß und deutlich einsetzt. Die Formen wirken frisch. An der entscheidenden Stelle des Herrenberges liegt die Kiesgrube (Fig. 8), die von KnaUer (1954) als Kronzeuge für seine These angerufen wird, wonach die Zürichphase des Reußgletschers alt und von allen Würmvorstößen überfahren worden sei. Wir können uns dieser Auffassung, wie die vorausgehenden und die nachfolgenden Ausführungen zeigen, nicht anschließen. Die Kiesgrube vom Herrenberg beweist übrigens das Gegenteil der KNAUER'schen Auffassung.

Auf der Südseite des Einganges zur Kiesgrube ist über normal aussehendem Moränenmaterial eckiger Schutt aufgeschlossen, der hier auch die Oberfläche bildet. Die Moräne ist der Rest des äußern Moränenkranzes und in den Wall des Herrenberges mit einbezogen (Fig. 9). Beim Vorstoß der zweiten Phase floß das Hangwasser des Erlosenberges vereint mit Schmelzwasser gegen den äußern Moränenkranz und durchibrach ihn südlich des Herrenberges, wobei jener auf größere Strecken vernichtet wurde. Beim Herrenberg gabelte sich der Bach. Der eine Ast floß gegen Kleinzelg und Ermensee, der andere strömte zwischen der äußern Moräne und der vorstoßenden Gletscherzunge dahin. Die Moränengrundlage wurde dabei verschwemmt und mit gerolltem Material vermischt. Mit Annäherung der Gletscherzunge an den äußern Wall stürzten von der steiler werdenden Stirn Oberflächenmoränen ins Wasser und wurden ausgewaschen So bildete sich eine Blocklage, die den Schotter nach oben abschließt. Mit dem weitern Vorstoß wurde sie mit Moräne zugedeckt, die auf der Innenseite am mächtigsten werden mußte. Diese Moräne nimmt gegen die Außenseite hin schnell an Mächtigkeit ab und fehlt am Eingang zur Kiesgrube bereits ganz. Daher bildet hier die durch Auswaschung entstandene Schicht aus Bodenskelett auch die Oberfläche. Dies und die

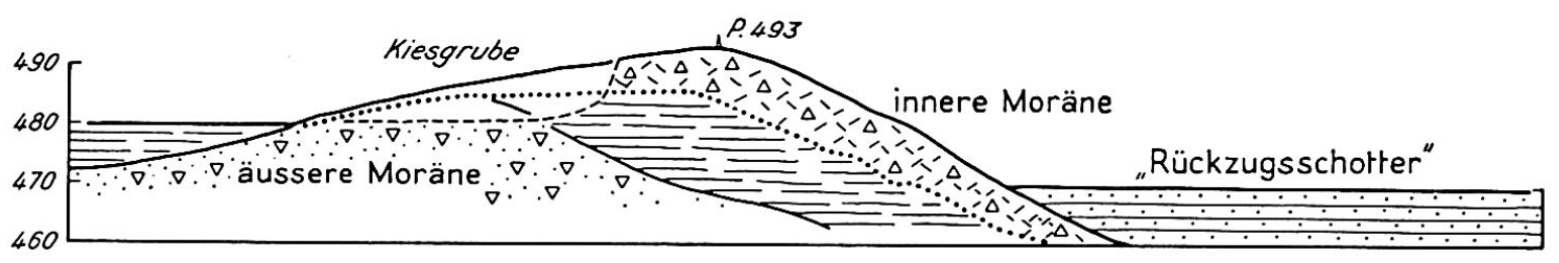

Fig. 9 Querschnitt durch die Herrenbergmoräne, schematisch. Punktreihe = Blocklage; "waagrecht schraffiert $=$ Vorstoßschotter; waagrecht schraffiert mit Punkten $=$ "Rückzugsschotter ${ }^{\prime \prime}$ (Entwurf A. BöGLI, Zeichnung B. BAUR). 
außerordentlich frisch wirkende Form des Herrenberges mit der steilen Innenseite und der flachen Außenböschung schließen die KNaUer'sche Auffassung von einem Frühwürmalter der Moränen der Phase aus.

Der Schützenhubel mit der Grünenburg gehört zum gleichen jugendlich aussehenden Walltyp des innern Kranzes wie der Herrenberg. Allerdings liegt er $300 \mathrm{~m}$ vom äußern Moränenkranz entfernt. Wenn auch hierdurch die Verhältnisse von jenen des Herrenberges etwas abweichen, so spielen sich doch ähnliche Vorgänge wie dort ab. Das Wasser der Hänge zwischen Dünkel- und Schließbach, voraussichtlich durch Schmelzwasser verstärkt, ergießt sich in den Raum zwischen der Gletscherstirne und dem äußern Walle. Es bildet sich ein Schmelzwassertal, das sich einschneidet und damit ein Erosionsniveau 5 bis $10 \mathrm{~m}$ unter der Schotterfläche des äußern Kranzes schafft. Die Schotterfläche streicht daher gegen $\mathrm{S}$ ins Leere aus. Außerdem erodierte das Wasser auch den neuen, sich bildenden innern Wall, sodaß dessen Außenseite heute stellenweise steiler ist als die Innenseite, eine Umkehrung der ursprünglichen Verhältnisse. Das Wasser ergoß sich gegen den Raum der heutigen Mosterei und zerstörte den äußern Wall zwischen Herrenberg und Großhübel, was durch die groben Schotter in einer Baugrube von Ermensee deutlich bewiesen wird. Weiter draußen vereinigten sich diese Schotter mit den alten der ersten Phase und bildeten eine einheitliche Sanderebene.

Auch im Schützenhubel gibt es eine Kiesgrube. Die Schotter sind im hintersten Teile eben noch angeschnitten. Es hat sich hier kein Blockhorizont ausgebildet, sondern es entstand ein lehmiges Sandband, das im Bild deutlich als feuchte, dunkle Zone hervortritt. Das weist darauf hin, daß es zur Bildung einer ruhigen Wasserfläche kam. Auch hier schob sich der Gletscher auf die Schotter hinauf. Dabei wurden Moränen, Schotter und Sandband in komplizierter Eistektonik mit einander verknetet (Fig. 10) und zuletzt noch mit Moräne überlagert.

Der Gletscherfluß der zweiten Phase hat möglicherweise den äußern Wall und die anschließenden Schotter in einem 'Trompetentälchen durchschnitten. Heute ist hiervon nichts mehr zu sehen. Es kann sein, daß wegen der starken Schotterführung die Form nicht sehr ausgeprägt war. Hauptsächlich wird aber die Ursache darin liegen, daß.

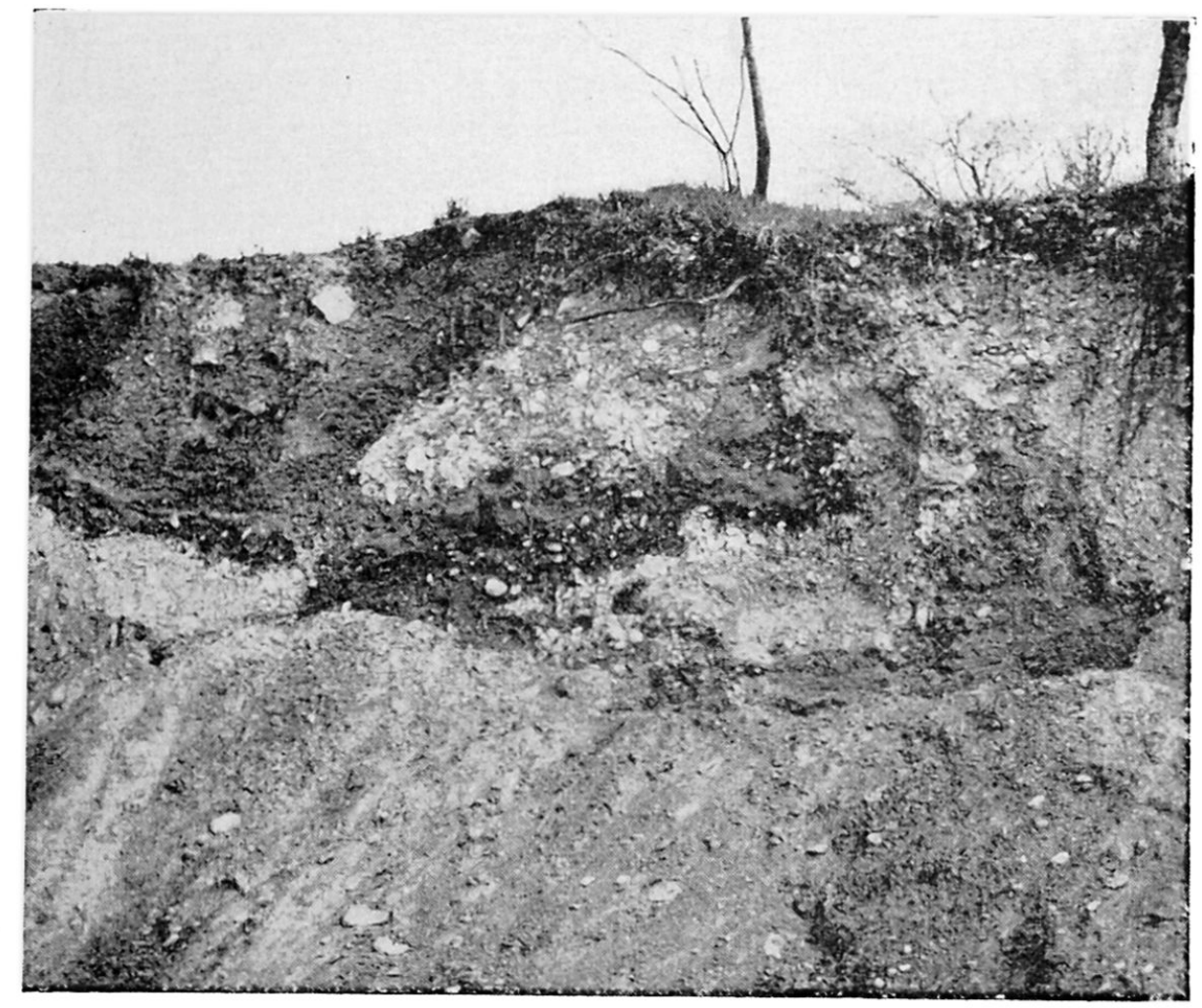

Fig. 10 Schützenhubel: Eistektonik. Paket von schottriger Moräne in Lehmsand eingewickelt (Photo A. Bögli). 
dichte Lehme die gesamte Oberfläche überdecken und dadurch die ursprünglichen Formen weitgehend ausgleichen. Diese Lehme sind nachrömischen Alters, was durch Funde bei Hochdorf gesichert ist. Sie dürften frühmittelalterlich sein (s.BögLI,1951), wobei die Holzkohlenfunde in die Zeit ausgedehnter Brandrodungen weisen. Damit wäre der bis zu $3 \mathrm{~m}$ mächtige Lehm als Auelehm zu bezeichnen. Die KNAuer'sche Auffassung, die Abdichtung gehe auf Grundmoräne zurück, ist danach nicht haltbar, obschon in der Nähe der Talränder im Hangfuß abgerutschte Moränen vorkommen und sich in den seitlichen Schwemmkegeln verschwemmtes Moränenmaterial befindet, das in den Hochwasserbildungen moränenartig aussieht.

An den innern Moränenkranz schließt sich eine Schotterplatte von unterschiedlicher, stellenweise $500 \mathrm{~m}$ überschreitender Breite an. Gegen das Beckeninnere folgt im Bereiche eines früheren Seestandes Flachmoortorf, unterlagert von Seekreide. Die Schotterplatte entstand durch Anschüttung an eine Toteismasse im Niveau des früheren Abflusses von $470 \mathrm{~m}$ Höhe (BöGli 1951). Diese Toteismasse schützte den Baldeggersee vor der Zuschüttung durch die reichlichen Schuttmassen, die nach dem Verschwinden des Gletschers gegen das Beckeninnere geführt wurden. Deshalb liegt die tiefste Stelle des Baldeggersees $5 \mathrm{~m}$ tiefer als im weiter talabwärts befindlichen Hallwilersee.

Zum Stirnmoränenkranz von Ermensee gehört als korrelate Form das Zungenbecken Es wirkt ebenso frisch wie das Zungenbecken des Sempachersees oder der Reußebene südlich Bremgarten. In ihrer Verknüpfung mit den Stirnmoränen bilden sie einen weitern Beweis in der Kette der vielen Beweise, daß die Rückzugsphase von ErmenseeHitzkirch jünger ist als die beiden andern weiter nördlich.

\section{ERGEBNISSE ÜBER DIE ENDMORÄNENPHASEN DES SEETALES}

a) Phase $B$ (Seon, Maximalstand): Die Phase ist vertreten durch vier Endmoränenbögen, von denen der äußerste relativ weit von den innern, unmittelbar hintereinander gestaffelten entfernt ist. Sie sind von außen nach innen nacheinander entstanden und zeigen noch weitgehend die vom Gletscher geschaffene Formung; Erosionsformen haben nur beschränktes Ausmaß und sind fluvial bedingt (Schmelzwassertälchen, Durchbruch des Talgewässers). Die Moränen liegen VorstoßSchottern auf.

b) Phase A (Seengen): Die fünf Wälle dieser Phase verteilen sich auf eine Distanz von $4 \mathrm{~km}$ im Talboden zwischen Seon und Seengen. Auf Grund der morphographischen Befunde wird gefolgert, daß sie vom Gletscher überfahren und gründlich überarbeitet worden sind. Der Eisdruck hat dabei in der Talmitte die Moränen z.T. völlig niedergeschliffen oder - in oft drumloider Umprägung - zu flachwelligen Erhebungen reduziert. Die seitlichen Teile der Endmoränen und die Seitenmoränen konnten dem Eisdruck besser widerstehen, und nur Buckel und Kuppen wurden geglättet. Der innere Aufbau dieser Moränen konnte mangls guter Aufschlüsse nicht beobachtet werden.

c) Phase C (Ermensee-Hitzkirch, «Zürich-Stadium»): Sie wird durch zwei hintereinander gestaffelte Endmoränenkränze dokumentiert, von denen der äußere aus fla* chen, der innere aus teilweise steil nach innen geböschten, in Einzelwälle aufgelösten Erhebungen besteht. Der innere Aufbau der Moränen ist kompliziert, läßt jedoch eine Überlagerung der Wallformen durch eine jüngere Grundmoräne nirgends erkennen. Die beiden Stirnmoränen sind daher - im Gegensatz zur Auffassung KNAUERS - nicht von einem über sie vorrückenden Gletscher überfahren worden. Die extramorän den Talboden überdeckenden Lehme sind nicht Grundmoräne, sondern nachrömische Auelehme.

d) Es hat sich erneut gezeigt, daß die Deutung von Moränenaufschlüssen überaus schwierig ist; Grundmoräne und Wallmoräne sind meist schwer auseinanderzu- 
halten. Nur wo einwandfrei diagnoszierbare interstadiale Bildungen zwischen Moränen eingeschaltet sind, ist die Zugehörigkeit der beiden Moränenbildungen zu zwei verschiedenen Stadien wirklich erwiesen.

e) Es ergibt sich sonach folgende chronologische Entwicklung:

1. Bildung der (Vorstoß-) Niederterrassenschotter während des Vorrückens des Gletschers, vielleicht synchron mit den Eisrandlagen der Phase A.

2. Ablagerung der 5 Endmoränenbögen der Phase A (Frühwürm, «Vorrückungsphase»).

3. Eisvorstoß bis zum Maximalstand (nach zwischengeschaltetem Rückzug?) : Ablagerung der Stirnmoräne 1, dann Rückzug um einige hundert Meter und nacheinander Aufbau der Moränenbögen 2-4, an denen Trompetentälchen (TrolL, 1926) wurzeln (äußere Jungmoränen, Hochwürm).

4. Rückzug unbekannten Ausmaßes, mindestens kleiner Vorstoß mit Ablagerung von Vorstoß-Schottern gegen den Hallwilersee zu und der beiden Stirnmoränen der Phase C, wobei zuerst der äußere, darauf der innere Kranz gebildet wird (innere Jungmoränen, Spätwürm). Nach dem Eisrückzug Ablagerung der intramorän an die Phase $\mathrm{C}$ angelagerten Schotter und in nachrömischer Zeit Bildung der Auelehme.

Im Hinblick auf die Ansicht KNAUERs kann daher zusammenfassend festgestellt werden, daß wohl eine überfahrene Phase vorhanden ist; diese ist jedoch nicht die Zürich-Phase, sondern die fünf Endmoränenbögen aufweisende Phase (A) zwsichen jener und dem Maximalstand.

f) Interstadiale Bildungen sind aus dem Seetal und dem weitern Gebiet des würmzeitlichen Reußvorlandgletschers nicht bekannt. Die Zerschneidung der Niederterrassenschotter begann während der Maximalphase und hatte die Entstehung einiger Erosionsniveaus zur Folge. Es sind im zentralen Mittelland bisher nirgends in die Niederterrasse eingeschachtelte stadiale Schotterbildungen festgestellt worden, wie man immer wieder anzunehmen scheint. Im Gegenteil belegen zahlreiche Aufschlüsse die Erosionsnatur der in den Niederterrassenkörper eingesenkten Terrassenfelder (vgl. auch Moser und die soeben erschienene Arbeit von LeEMANN, der für das Rheintal zwischen Dießenhofen und Koblenz zur gleichen Ansicht gelangt). Es liegen somit keinerlei Beweise für warmzeitlich bedingte stärkere Eisrückzüge zwischen den Phasen $A$ und $B$ oder $B$ und $C$ vor. Da seit EBERL der Begriff «Stadium» meist im Sinne eines Gletschervorstosses nach einem beträchtlichen Eisrückgang verwendet wird - PENCK und BRÜCKNER reservierten ihn bekanntlich für die spätern Rückzugshalte Bühl - Daun -, so halten wir es für richtig, die Eisrandlagen A bis $\mathrm{C}$ als Phasen zu bezeichnen (vgl. Rathjens, 1954, p. 17, 1955, p.81). Damit soll die Möglichkeit stadialer Entwicklungen nicht von der Hand gewiesen werden. Doch bieten unsere Befunde vorderhand keinerlei Hinweise, eine Aufteilung der Phasen auf Würm I und II in Diskussion zu ziehen, und dies umso weniger, als heute manche der in dieser Hinsicht vorgenommenen $\mathrm{Zu}$ ordnungen fraglich geworden zu sein scheinen.

\section{PARALLELISIERUNG DER PHASEN IM REUSSGLETSCHERGEBIET}

Die im Seetal festgestellte raumzeitliche Struktur der Phasengliederung gilt für den ganzen Raum des würmzeitlichen Reußgletschers und vermutlich auch für die benachbarten Vergletscherungsgebiete (vgl. Fig. 3, Suhrental: Phase A Triengen, B Staffelbach; Bünztal: A Wohlen, C Waltenschwil; Reußtal: C Bremgarten). Ohne auf Details eintreten und der im Gange befindlichen Untersuchung vorgreifen zu wollen, sei doch eine auf früheren Publikationen und eigenen Beobachtungen basierende knappe Übersicht der drei Haupteisrandlagen gegeben, die allerdings in einigen Punkten noch nicht völlig gesichert ist (Fig. 1, Tab. 1). Es ist bezeichnend, daß gerade die überfah- 
Tab. 1: Lage der Würmphasen A, B und C in den Tälern des aargauisch-luzernischen Mittellandes

\begin{tabular}{l|l|l|l} 
& $\begin{array}{l}\text { Würm B } \\
\text { äßere Jungmoränen } \\
\text { Maximalstand } \\
\text { Hochwürm }\end{array}$ & $\begin{array}{l}\text { Würm A } \\
\text { überfahrene Moränen } \\
\text { Vorrückphase } \\
\text { Frühwürm }\end{array}$ & $\begin{array}{l}\text { Würm C } \\
\text { innere Jungmoränen } \\
\text { Rückzugsphase } \\
\text { Spätwürm }\end{array}$ \\
\hline Reußtal & Mellingen & Stetten & Bremgarten \\
\hline Bünztal & Othmarsingen & Dottikon, Wohlen & $\begin{array}{l}\text { Waltenschwil, Bünzen, } \\
\text { Boswil }\end{array}$ \\
\hline Seetal & $\begin{array}{l}\text { Seon } \\
\text { (4 Endmoränen) }\end{array}$ & $\begin{array}{l}\text { Seon, Seengen } \\
\text { (5 Endmoränen) }\end{array}$ & $\begin{array}{l}\text { Hitzkirch } \\
(2 \text { Endmoränen) }\end{array}$ \\
\hline Winental & Zetzwil, Gontenschwil & Menziken, Beromünster & Neudorf, Gormund \\
\hline $\begin{array}{l}\text { Suhrental } \\
\text { Hürnbachtal } \\
\text { Rontal }\end{array}$ & $\begin{array}{l}\text { Staffelbach } \\
\text { Dagmersellen } \\
\text { Egolzwil, Ettiswil }\end{array}$ & $\begin{array}{l}\text { Triengen } \\
\text { Buchs } \\
\text { Seewagen, Mauensee }\end{array}$ & Sursee \\
\hline Rottal & Großwangen & Stalten, Rüediswil & Moos, Unter Ziswil \\
\hline $\begin{array}{l}\text { Limmattal } \\
\text { Rheingebiet }\end{array}$ & $\begin{array}{l}\text { Killwangen } \\
\text { Neuhausen, Rüdlingen }\end{array}$ & $\begin{array}{l}\text { Schlieren } \\
\text { Dießenhofen }\end{array}$ & $\begin{array}{l}\text { Zürich } \\
\text { Stein a. Rh., Singen }\end{array}$
\end{tabular}

rene und reich differenzierte A-Phase ( 5 Eisrandlagen!) dabei die größten Schwierigkeiten bietet. Noch abzuklären sind - besonders durch eine konsequente Verfolgung der nur in ihren Hauplinien bekannten Seitenmoränenzüge, die Lage und Gliederung der A- und C-Phase im Bünztal, sodann die komplizierten Verhältnisse im Bereich der Maximal- und A-Phase im Winental. Hatte MühlBerg (1910, p. 38) angenommen, daß sich der Gletscher nach dem Maximalstand rasch aus dem Tale zurückgezogen habe, so wissen wir heute, daß die Phase A - allerdings als «Vorrückungsphase» - bis Beromünster, ja wahrscheinlich bis in die Gegend von Menziken hinunter reichte; dagegen war das Becken von Reinach damals tatsächlich eisfrei, haben doch unsere Aufnahmen (Annaheim und Moser) die Auffassung Mühlbergs bestätigt, wonach die Seetalzunge der A-Phase durch die Öffnung von Beinwil gegen das Winental westwärts ausbog. Die genaue Kartierung Kopps hat überdies gezeigt, daß auch in der ersten Zeit der Rückzugsphase $\mathrm{C}$ in der Gegend von Neudorf noch eine kurze Zunge ins Winental hinüber griff. Wenig durchsichtig sind außerdem die Zusammenhänge zwischen dem A-Suhrentalarm und dem synchronen Winentalast einerseits und dem breiten, ins Rontal vorstoßenden Eislappen andrerseits. Die Gestaltung des kurzen, durch den Emmenberg in seiner Entwicklung behinderten Rottalarmes macht es wahrscheinlich, daß nicht die weit vorgeschobenen Moränen von Großwangen (KoPP), sondern die rundlichen Wallformen von Stalten der A-Phase entsprechen (s. unten).

In diesem Zusammenhang sei noch auf die Frage der vordersten Würmmoränen hingewiesen, die vielerorts nur schlecht oder gar nicht mehr erhalten zu sein scheinen; MüHLberg (1910 p. 37) hat auf die junge Moränenstreu vor den Maximalmoränen hingewiesen, BRÜCKNER (p. 498) kennt sie ebenfalls, und FREY (p. 410 f.) versucht daraus im Wiggertal vor den Endmoränenbögen von Egolzwil-Ettiswil einen weitern, vorgelagerten Moränenkranz zu rekonstruieren. Moser hat Moränen dieser Art im See- und Bünztal kartiert.

Der Anordnungsmodus der Phasen in den einzelnen Tälern zeigt bezeichnende örtliche Differenzierungen (Tab. 2). Es zeigt sich zunächst ganz allgemein, daß die Ansicht Brückners (p. 502), wonach die Distanz zwischen den Phasen B und A überall kleiner sei als zwischen $A$ und $C$, nicht zutrifft; sie gilt in unserm Raum nur für das Seetal, welches jedoch gerade in dieser Hinsicht abnorme Verhältnisse aufweist (s. unten). Die mittlere Distanz zwischen B und A beträgt $5,7 \mathrm{~km}$, zwischen $\mathrm{A}$ und $\mathrm{C}$ 
Tab. 2: Entfernung der drei Haupt-Eisrandlagen von der Emme-Reuß-Niederung ( Littau-Emmen-Honau)

\begin{tabular}{|c|c|c|c|c|c|c|c|}
\hline & \multicolumn{2}{|c|}{$\begin{array}{l}\text { Übergang zur Emme-Reuß- } \\
\text { Niederung }\end{array}$} & \multicolumn{5}{|c|}{$\begin{array}{c}\text { Entfernung von der Emme-Reuß- } \\
\text { Niederung }{ }^{1}\end{array}$} \\
\hline & $\begin{array}{l}\text { Höhe } \\
\mathrm{m}\end{array}$ & Untergrund & $\begin{array}{l}\text { B-Phase } \\
\mathrm{km}\end{array}$ & & $\begin{array}{l}2 \\
0 \% 0^{2}\end{array}$ & & $\begin{array}{l}\mathrm{se} \\
0 \%\end{array}$ \\
\hline Reußtal & 400 & Quartär (Talsohle) & 34 & 29 & $0=$ & 22 & $6=$ \\
\hline Bünztal & & & 33 & 27 & & 22 & \\
\hline Seetal & 500 & Quartär & 33 & 29 & 02 & 16 & \\
\hline Winental & 700 & Molasse $^{3}$ & 26 & 19 & 73 & 13 & 50 \\
\hline Suhrental & 540 & Molasse & 30 & 25 & 83 & 17 & 68 \\
\hline Rottal & 680 & Molasse & 21 & 14 & 67 & 9 & 43 \\
\hline
\end{tabular}

1 gemessen längs der Achse der Gletscherzungen (Täler), bei der B- und C-Phase bis zu den äußersten Endmoränen, bei der A-Phase bis zur Mitte zwischen äußersten und innersten Vorkommen, da diese über weite horizontale, lokal variable Distanzen verteilt sind.

2 Die Prozentangaben sind bezogen auf die Gesamtlänge der Eisäste während des Maximalstandes (gemessen ab Emme-ReuB-Niederung); sie sollen einen Vergleich der Intensität des Eisvorstoßes oder -rückganges der verschiedenen Zungen ermöglichen.

3 mit aufgelockerter Quartärdecke.

$5,1 \mathrm{~km}$ (ohne Seetal). Die Reliefverhältnisse haben, sei es direkt oder aus weiterer Entfernung, die Eisrandlagen der verschiedenen Teilarme stark beeinflußt, wobei sich Reliefhindernisse mit zunehmendem Schwund der Eismächtigkeit immer stärker auswirkten. Infolge der hohen Molasseschwelle sind daher die Gletscherzungen des Rotund Winentales während aller Eisrandlagen nicht nur absolut kürzer als jene der andern Täler, sondern liegen zur Zeit der Phasen $\mathrm{A}$ und $\mathrm{C}$ mit ihrem niedrigen Eisstand auch relativ weiter zurück als in den tieferen Talfurchen: die relative Distanz zwischen $\mathrm{B}$ und $\mathrm{A}$ beträgt im Winental $27 \%$, im Rottal $33 \%$, in den übrigen Tälern im Mittel 16\%. Damit steht offenbar in Zusammenhang, daß die sonst meist aus zwei eng gepaarten Wällen aufgebaute Phase $\mathrm{C}$ im obersten Winental mehrere hintereinander gestaffelte Moränenkränze aufweist und im Rottal wohl nur zwei Wallzüge (Moos, Unter Ziswil) besitzt, deren innerer jedoch erst $2 \mathrm{~km}$ südlich des äußern erscheint.

Kein Zufall scheint es sodann zu sein, daß die Winentalzunge trotz höherer Molasseschwelle $5 \mathrm{~km}$ weiter nordwärts vorstößt als die Rottalzunge; das Winental setzt unmittelbar jenseits der westlichen Austrittspforte des Reußeises ein, während das Rottal linksseitig abliegt und, wie KopP gezeigt hat, nur von Aareeis überflutet wurde. Am auffallendsten ist jedoch, daß die C-Phase des Seetales trotz geringer Schwellenhöhe relativ beträchtlich weiter zurücklag als in den früheren Phasen; sie sollte angesichts des bedeutenden Ausmaßes des Maximalvorstoßes und der sich bei allen übrigen Eisarmen ergebenden relativen Distanzwerte ca. $6 \mathrm{~km}$ nördlich von Hitzkirch im Hallwilersee - auf der Höhe von Beinwil - liegen. Diese Abnormität hängt offenbar damit zusammen, daß während der C-Phase der Diffluenzsporn der Rigimasse eine gewisse Erniedrigung der Eisoberfläche im oberen Seetal bewirkte, während die direkt vor den Alpentoren des Zuger- und Luzernersees gelegenen Furchen des Reuß- und Suhrentales von den zentralen Eismassen der beiden alpinen Hauptarme durchflossen wurden. Daher finden sich die C-Moränen im Reußtal noch weit vom Alpenrand entfernt, und selbst im Suhrental erreicht der synchrone Eisrand nahezu die gleiche Entfernung vom Luzerner Tor wie die Seetalzunge. Während der Phasen $\mathrm{A}$ und $\mathrm{B}$ waren die Eisstromverhältnisse offenbar insofern andere, als damals das Eis im Seetal viel weiter nordwärts eindrang als im Suhrental. 
Es ist ersichtlich, daß der Quartärforschung im zentralen Molasseland noch zahlreiche Aufgaben warten. Besonders aufschlußreich dürfte die Erforschung der Entwässerungsverhältnisse zur Zeit der drei Hauptphasen sein, wobei namentlich die Gestaltung des Gewässernetzes während der A-Phase und die Frage seiner Vererbung über den maximalen Gletschervorstoß hinweg auch für die Deutung der Phase selbst bedeutungsvoll erscheint.

\section{LITERATURVERZEICHNIS}

1 Bögli A. (1951): Die Entstehung des Baldeggersees. Heimatkunde aus dem Seetal, 25.

2 Bögli A. (1955): Aus der Arbeit der Schweiz. Geomorphologischen Gesellschaft. Geographica Helvetica 10 , p. $100 \mathrm{f}$.

3 Eberl B. (1930): Die Eiszeitenfolge im nördlichen Alpenvorlande. Augsburg.

4 FreY O. (1907): Talbildung und glaziale Ablagerungen zwischen Emme und Reuß. Denkschrift Allg. Schweiz. Naturf. Ges. 41

5 Herm A. (1919): Geologie der Schweiz, Bd. 1. Leipzig.

6 JäCKLI H. (1956): Talgeschichtliche Probleme im aargauischen Reußtal. Geogr. Helv. 11, p. 46-59.

7 Kaufmann F. J. (1872): Beiträge zur geol. Karte der Schweiz, 11.

8 KNauer J. (1935): Die Ablagerungen der älteren Würm-Eiszeit (Vorrückungsphase) im süddeutschen und norddeutschen Vereisungsgebiet. Abhdl. Geol. Landesuntersuchung am Bayr. Oberbergamt, H. 21, München.

9 KNauer J. (1937): Widerlegung der Einwendungen K. Troll's gegen die Vorrückungsphase der Würm-Eiszeit. Mitt. Geogr. Ges. München, 30.

10 KNauer J. (1938): Über das Alter der Moränen der Zürich-Phase im Linthgletschergebiet. Abhdl. Geol. Landesuntersuchung Bayr. Oberbergamt, H. 33, München.

11 KNauer J. (1954): Über die zeitliche Einordnung der Moränen der Zürich-Phase im Reussgletschergebiet. Geogr. Helv. 9, p. 71-85.

12 Kopp J. (1945): Geol. Atlas der Schweiz 1:25'000, Blatt 18, mit Erläuterungen. Bern.

13 Leemann A. (1958): Revision der Würmterrassen im Rheintal zwischen Dießenhofen und Koblenz. Geogr. Helv. 13, p. 89-173.

14 Moser S. (1958): Studien zur Geomorphologie des zentralen Aargaus. Diss. Basel, Mskr. (erscheint demnächst).

15 Mühlberg F. (1910): Geol. Karte der Umgebung des Hallwilersees und des oberen See- und Winentales 1:25000, mit Erläuterungen. Aarau.

16 Möhlberg F. (1911): Der Boden des Aargaus. Festschrift zur Feier des 100-jährigen Bestehens der Aarg. Naturf. Ges. Aarau.

17 Penck A. u. Brückner E. (1909): Die Alpen im Eiszeitalter, Bd. 2, Leipzig.

18 Rathjens C. (1954): Das Problem der Gliederung des Eiszeitalters in physisch-geographischer Sicht. Münchner Geogr. Hefte, 6.

19 Rathjens C. (1955): Zur Frage der Gliederung der Würmeiszeit. Petermanns Geogr. Mitt. p. $81-87$.

20 Troll K. (1926): Die jungglazialen Schotterfluren im Umkreis der deutschen Alpen. Forschungen z. deutschen Landes- und Volkskunde, 24, H. 4.

21 Troll K. (1936): Die sogenannte Vorrückungsphase der Würm-Eiszeit und der Eiszerfall bei ihrem Rückgang. Mitt. Geogr. Ges. München, 29.

\section{THE PHASES OF WÜRM GLACIATION IN THE REGION OF THE REUSS GLACIER IN THE CENTRAL SWISS PLATEAU}

In the region of the Reuss glacier the terminal moraines of the Würm glaciation are developped in three distinct groups as follows: Phase B: 4 terminal moraines of the Würm maximum (Seon near Lenzburg; Hochwürm); they lie upon the Niederterrassenschotter (gravels of the low terrace), which were deposited during the glacial advance (Vorstoss-Schotter); beginning of the erosion by down-cutting and formation of erosion terraces in these gravels during the phase B. Phase A: A system of 5 frontal moraines (Seengen) about $4 \mathrm{~km}$ south of the maximal phase, with drumloid forms, degraded by the overriding glacier of the maximal progression (phase B); Vorrückphase (progressional phase), early Würm. Phase C: A third system of 2 terminal moraines (Hitzkirch) $13 \mathrm{~km}$ south of phase A. This moraine phase was not overrided by the glacier contrary to the opinion of Knauer. $C$ is the recessional phase (Rückzugsphase, Zürich-phase), late Würm. The following chronological structure of Würm glaciation results: progressional phase (early Würm, A) - progression to the maximal phase (Hochwürm, B) recessional phase (late Würm, C) - afterwards recession to the border of the Alps etc. Interstadial deposits not being observed, the phases are probably not real stages, therefore there does not existe actually any possibility of coordinating these phases to Würm I or to Würm II. Finally, parallelisation of these phases with the systems of terminal moraines in the other valleys of the region of the Reuss glacier is discussed. 